\title{
A Fatigue Crack Growth Model for Random Fiber Composites
}

\author{
D. R. ATODARIA* AND S. K. PUTATUNDA** \\ Department of Materials Science and Engineering \\ Wayne State University \\ Detroit, MI 48202 \\ P. K. MALLICK $\dagger$ \\ Department of Mechanical Engineering \\ University of Michigan-Dearborn \\ Dearborn, MI 48128-1491 \\ (Received May 7, 1996) \\ (Revised September 27, 1996)
}

\begin{abstract}
Fatigue crack growth behavior of a randomly oriented short carbon fiber reinforced polyether ether ketone (PEEK) composite is studied at four different load ratios. Based on the experimental data, a new fatigue crack growth model is proposed which accounts for crack growth throughout the entire fatigue cycle and not just at the maximum load. The proposed model involves a weighted averaging procedure and is found to fit the fatigue crack growth rates at all load ratios in a single power law equation. Finally, it is observed that the fatigue threshold intensity of this material decreases with increasing load ratio.
\end{abstract}

\section{INTRODUCTION}

T T IS NOW well established that the fatigue crack growth rate, $d a / d N$, in metals can be related to the stress intensity range, $K$, in the form of a power law,

$$
\frac{d a}{d N}=C(\Delta K)^{m}
$$

where, $C$ and $m$ are material constants and $\Delta K$ is the difference between the maximum and minimum Mode I or opening mode stress intensity factors in the fatigue cycle. Both $C$ and $m$ are determined by curve fitting experimentally measured fatigue crack growth data. The value of $m$ for metals is found to be between 2.5 and 4 .

* Graduate Research Assistant.

**Associate Professor.

†Professor and author to whom correspondence should be addressed. 
Equation (1), known as the Paris equation, is used for estimating the number of fatigue cycles required for the steady growth of a crack or a flaw from an initial detectable length $a_{i}$ to the critical length $a_{c}$. It is assumed that once the critical length $a_{c}$ is reached, the crack grows at a very rapid rate and the failure becomes imminent. On the other hand, if the stress intensity factor is less than the threshold value, $K_{t h}$, no crack growth is observed.

Even though the Paris equation is now commonly used to characterize the fatigue crack growth rate in metals, it has found only limited applications in fiber reinforced composites. In the case of laminated composites, the fatigue crack growth rate is modeled using a power law equation similar to Equation (1) using the strain energy release rate, $G$, as the controlling parameter instead of the stress intensity factor $K$ used for metals. The reason for this is that expressions for $K$ are not easily obtained for laminated structures with orthotropic layers. Furthermore, the major fatigue failure mode in laminated composites is delamination, at least in the initial stages of cycling. Delamination occurs due to out-of-plane interlaminar shear and normal stresses and is not a Mode I type failure.

Unlike laminated composites, randomly oriented short fiber composites are, for all practical purposes, considered isotropic materials and, therefore, the isotropic expressions for Mode I stress intensity factors may still be applicable. In recent years, the Paris equation has been used by many investigators to model fatigue crack growth rate in injection molded thermoplastic composites [2,3] as well as compression molded thermoset composites [4]. Some of these investigations examined the effects of material variables, such as fiber type, fiber length and fiber orientation, on the fatigue crack growth rate in these composites. The effects of fatigue test variables, such as frequency and load ratio, have been investigated to a very limited extent.

The motivation for the present work comes primarily from the observation that the fatigue damage in random fiber composites can develop at stresses that are much lower than the maximum stress level imposed in a fatigue cycle. Since the Paris equation is based only on the difference in the maximum and minimum stresses in a fatigue cycle, it does not take into account the effects of intermediate stresses on the damage development. Furthermore, the Paris equation does not take into account the effect of load ratio, which is seen to have a large effect on the fatigue crack growth rate of materials, in general. Several different empirical models have been proposed in the literature to account for the effect of load ratio in metals [5]. However, they are not always easy to use and they contain material properties or empirical constants that are not always available.

In the present work, we have studied the fatigue crack growth rate in a randomly oriented short carbon fiber reinforced polyether ether ketone (PEEK) composite at four different load ratios. Based on the experimental data on this material, we have examined the applicability of several different models, including the Paris model. One of these models, proposed in this work, is based on the assumption that the damage development and accumulation occurs in the entire fatigue cycle, which represents a more realistic condition for random fiber reinforced composites. The methodology used in fitting this model to the experimental data is discussed in this paper. The effect of load ratio on the fatigue threshold stress intensity factor is also presented. 


\section{EXPERIMENTAL PROCEDURE}

\subsection{Material}

The material used in the present investigation is a randomly oriented short carbon fiber reinforced PEEK composite supplied by Victrex USA, Inc. The commercial designation for the material is $150 \mathrm{CA} 30$. The nominal fiber content is 30 weight percent and the reported tensile strength of the material is $226 \mathrm{MPa}$. The matrix in this composite is polyether ether ketone or PEEK, which is a high temperature resistant thermoplastic polymer with a higher fracture toughness than many thermoset polymers used in the composites industry. This makes it an ideal material in critical structural components in both aerospace and automotive applications. However, very little information is currently available for the fatigue crack growth rate in this material.

\subsection{Fatigue Testing}

In this study, compact tension (CT) specimens were prepared as per ASTM Standard E-647 [6] from a $3.175 \mathrm{~mm}$ thick flat injection molded plate of this material. A schematic of the compact tension specimen used in this study is shown in

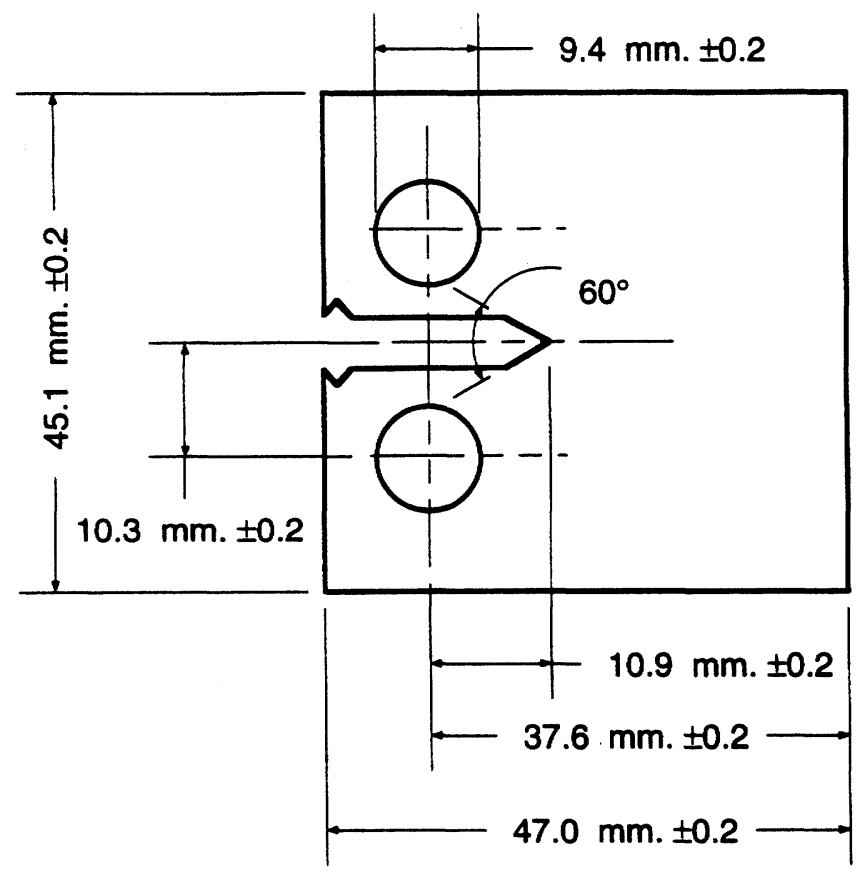

Figure 1. Compact tension specimen. 
Figure 1. The specimens were radiographically examined for any detectable voids or flaws before conducting the fatigue tests. The surfaces of the compact tension specimens were polished to remove the film of releasing agent and any shine that creates problems in detecting the crack accurately during fatigue testing. The specimens were initially precracked in fatigue to produce a $4 \mathrm{~mm}$-long sharp crack in accordance with ASTM Standard E-647. Precracking was carried out at a $\Delta K$ level of $4.5 \mathrm{MPa} \sqrt{\mathrm{m}}$. After fatigue precracking, fatigue tests were conducted using a servo-hydraulic MTS testing machine. All tests were at room temperature and in load control mode. A constant amplitude sinusoidal wave form was applied at four different load ratios, $R=0.00,0.10,0.30$, and 0.50 . The frequency of cycling was 2 $\mathrm{Hz}$. The crack length was monitored with the help of a traveling optical microscope.

The fatigue threshold was determined using the load shedding technique as per ASTM Standard E-647. This procedure involves slowly decreasing the load values and recording the crack growth rate. This load reduction was done only up to a maximum of $5 \%$ and also only after the crack had grown by at least $1 \mathrm{~mm}$ at the previous $\Delta K$ level. In this way any overload retardation effect caused by prior $\Delta K$ was avoided. The threshold was determined graphically from the plot of $\log \mathrm{da} / \mathrm{dN}$ versus $\log \Delta K$. The threshold was identified as the value of $\Delta K$ at which the crack growth rate was of the order of $10^{-10} \mathrm{~m} /$ cycle in accordance with ASTM Standard E-647. Three to four identical specimens were tested for each load ratio. The average values from these specimens were then taken as representative of crack growth rate data and the fatigue threshold.

\section{RESULTS AND DISCUSSIONS}

\subsection{Fatigue Crack Growth Rate}

Figure 2 shows the fatigue crack growth rate, $d a / d N$, of the material in consideration against $\Delta K$ in a $\log -\log$ plot for $R=0,0.1,0.3,0.5$. This figure shows that at a constant $\Delta K$, the fatigue crack growth rate in this material increases with increasing load ratio. Since $\Delta K=K_{\max }(1-R), K_{\max }$ must be increased to maintain $\Delta K$ constant at a higher load ratio [Figure 3(a)] and increasing the value of $K_{\max }$ results in the increase of crack growth rate. However, if, instead of $\Delta K, K_{\max }$ is used as the controlling parameter (Figure 4), it is observed that at a constant $K_{\max }$, the fatigue crack growth rate decreases with increasing load ratio. As Figure 3(b) demonstrates, at a constant $K_{\max }$, an increase in the load ratio $R$ means $\Delta K$ is decreased, and, thus, a decrease in fatigue crack growth rate with increasing load ratio in this case is due to a decreasing value of $\Delta K$. Power law equations can be fitted to the data for each load ratio in Figures 2 and 4; however, different power law constants will be obtained for different load ratios.

Since fatigue crack growth in random fiber composites can occur at each increment in load during a fatigue cycle, it was decided to plot the data using an average value of $K$. However, recognizing that the load level will have a great influence on the extent of crack growth, the following averaging procedure was adopted instead of using a simple geometric average: 


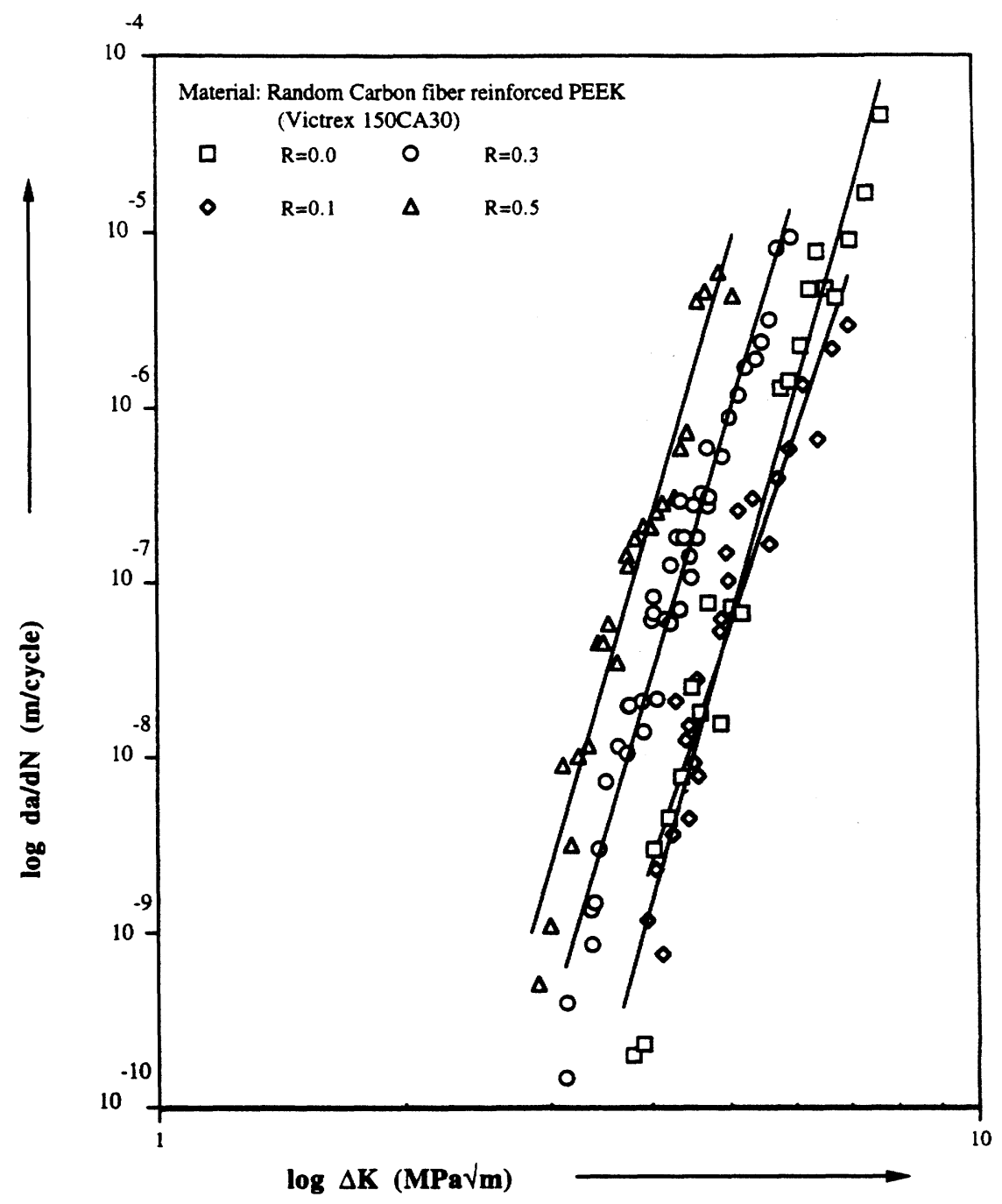

Figure 2. Effect of load ratio on da/dN vs. $\Delta \mathrm{K}$ 


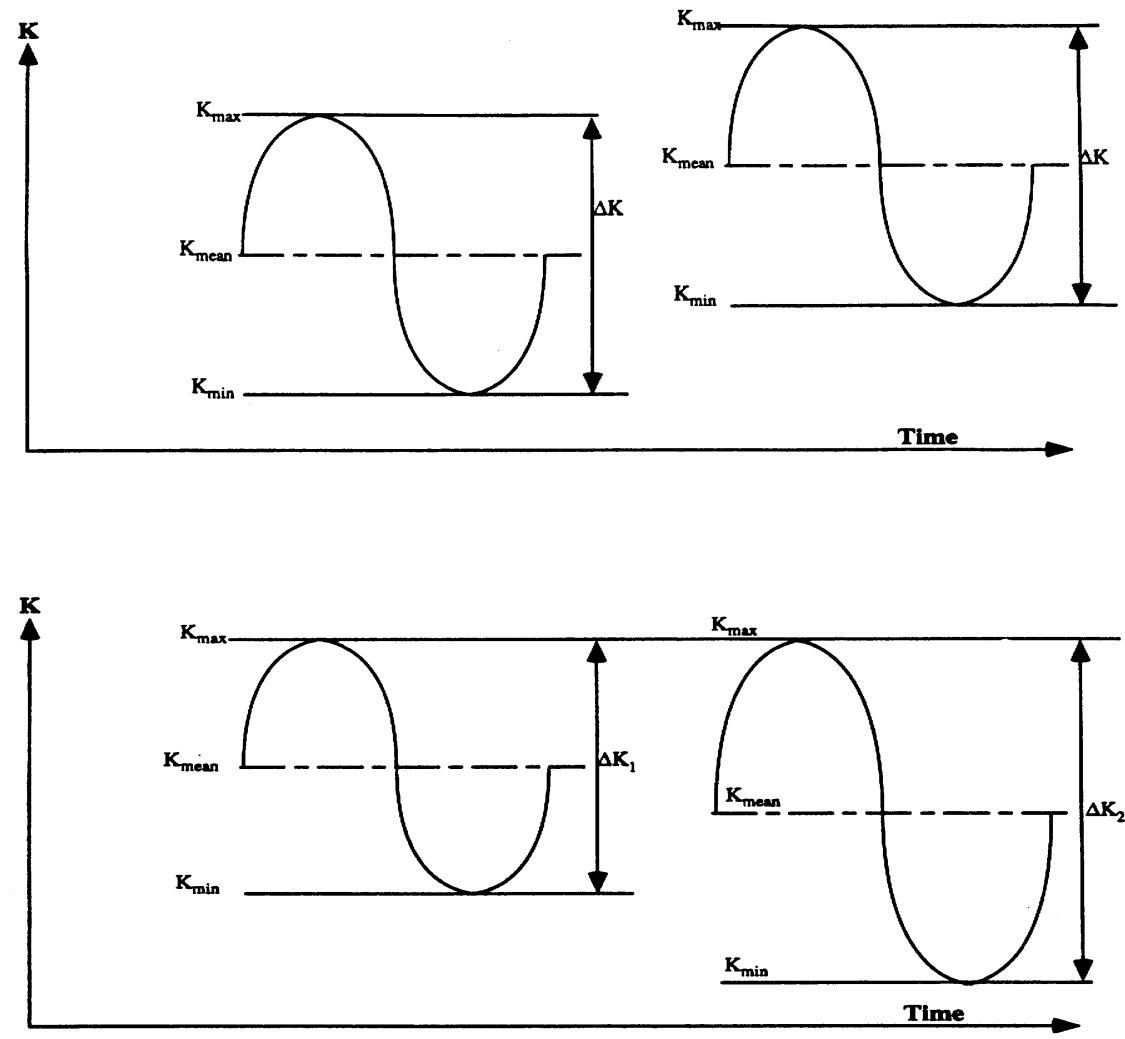

Figure 3. (a) Fatigue cycles with constant $\Delta \mathrm{K}$; (b) fatigue cycles with constant $\mathrm{K}_{\max }$. 


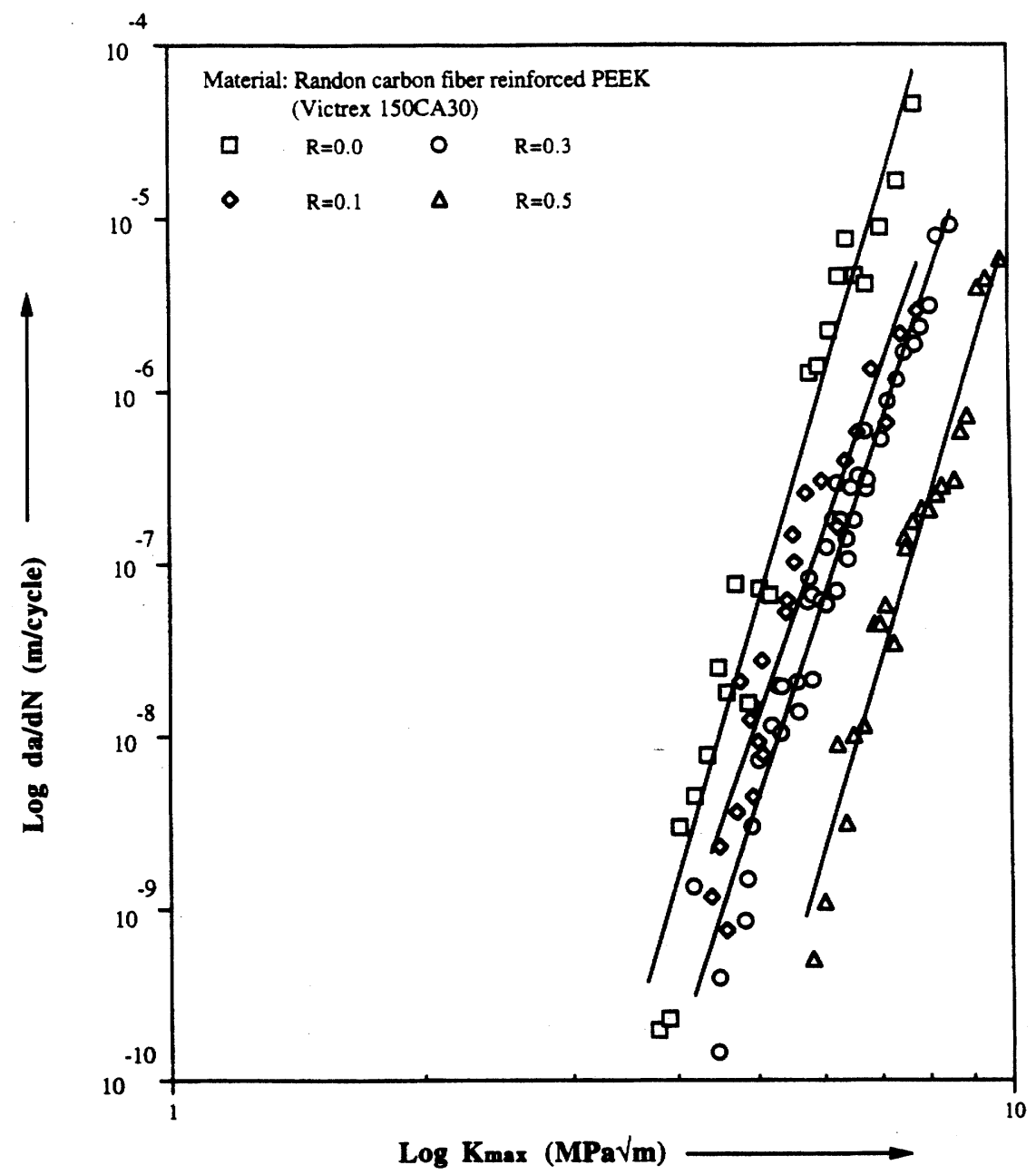

Figure 4. Effect of load ratio on da/dN vs. $\mathrm{K}_{\max }$. 


$$
K_{\text {average }}=\left[\frac{1}{n} \sum_{K_{t h}}^{K_{\max }} K^{w}\right]^{1 / w}
$$

where $n$ is the number of divisions by which the range $K_{t h}$ to $K_{\text {max }}$ is equally partitioned (Figure 5) and $w$ is a weighting factor. Note that $w$ is assumed here to be independent of the load level; however, its effect on $K^{w}$ is greater at high load levels than at low load levels. In this study, the value of $n$ was 100 and the starting value of the weighting factor $w$ was equal to the Paris power law exponent $m_{1}$. The algorithm used for determining the final value of $w$ is explained in the next section.

Figure 6 shows the log-log plot of $d a / d N$ vs. $K_{\text {average }}$ at the four load ratios used in this study. The initial value of $w$ was assumed to be the same as $m$ in the Paris equation, which was obtained by fitting Equation (1) to the data in Figure 2. It is seen in Figure 6 that, at a given $K_{\text {average }}$, the fatigue crack growth rate decreases with increasing load ratio. Since the load ratio has opposite effects with $\Delta K$ and $K_{\text {aver- }}$ age, the next logical choice is to plot the fatigue crack growth rate against $\sqrt{\Delta K \cdot K_{\text {average }}}$, which is shown in Figure 7 . It is now observed that the fatigue crack growth rate for all four load ratios merge into a very narrow band, indicating that a single straight line can represent the data for all four load ratios. If this is true, it should be possible to predict the fatigue crack growth for any load ratio after es-

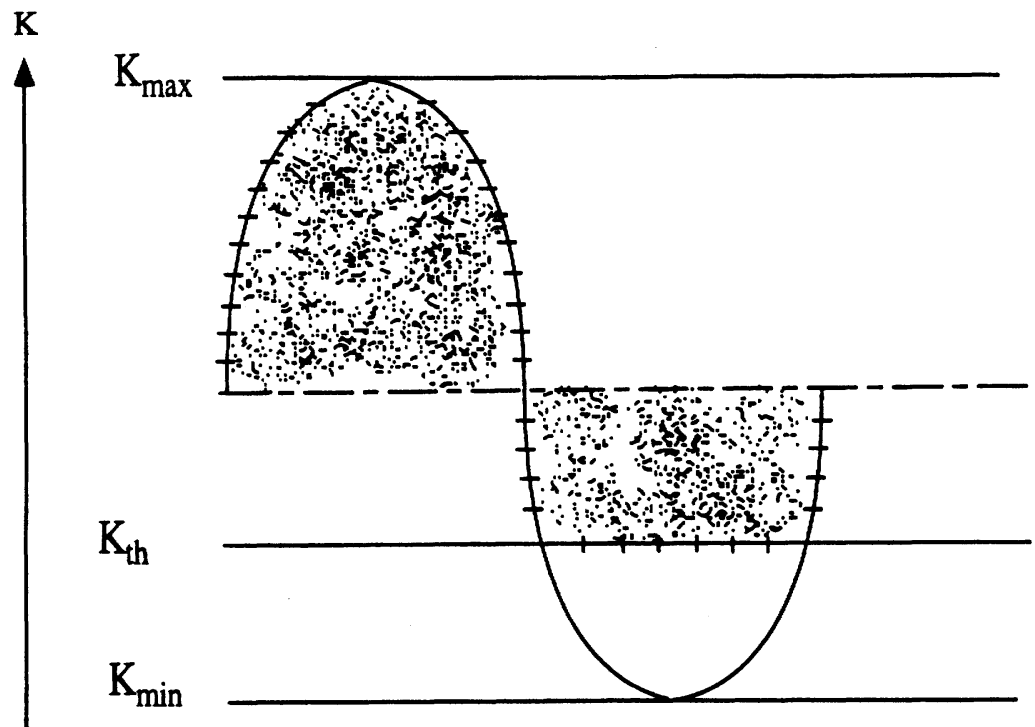

Time

Figure 5. Partition from $\mathrm{K}_{\mathrm{th}}$ to $\mathrm{K}_{\max }$ in $\mathrm{n}$ divisions for calculating $\mathrm{K}_{\text {average: }}$ 


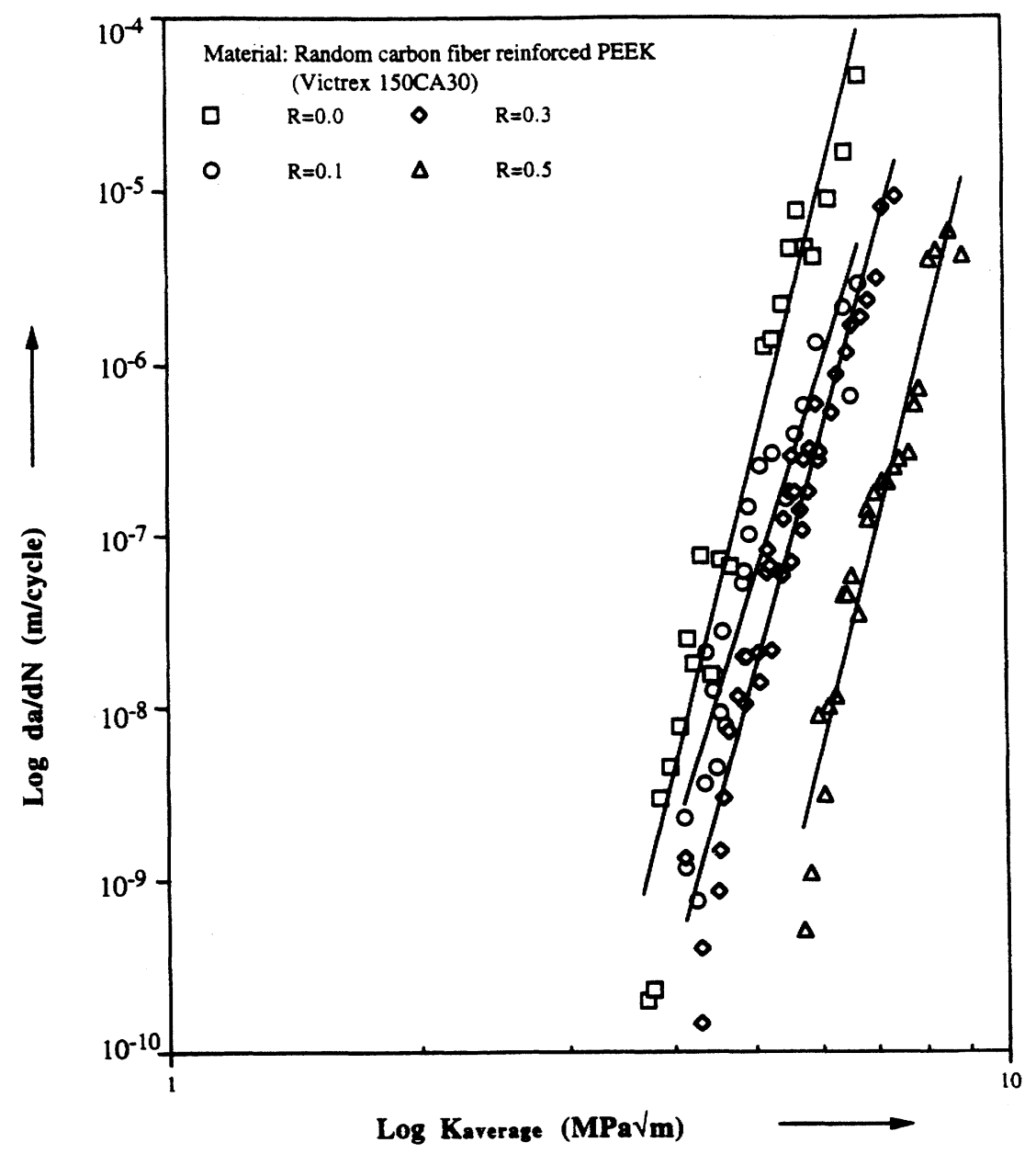

Figure 6. Effect of load ratio on fatigue crack growth behavior when computed against Kaverage. 


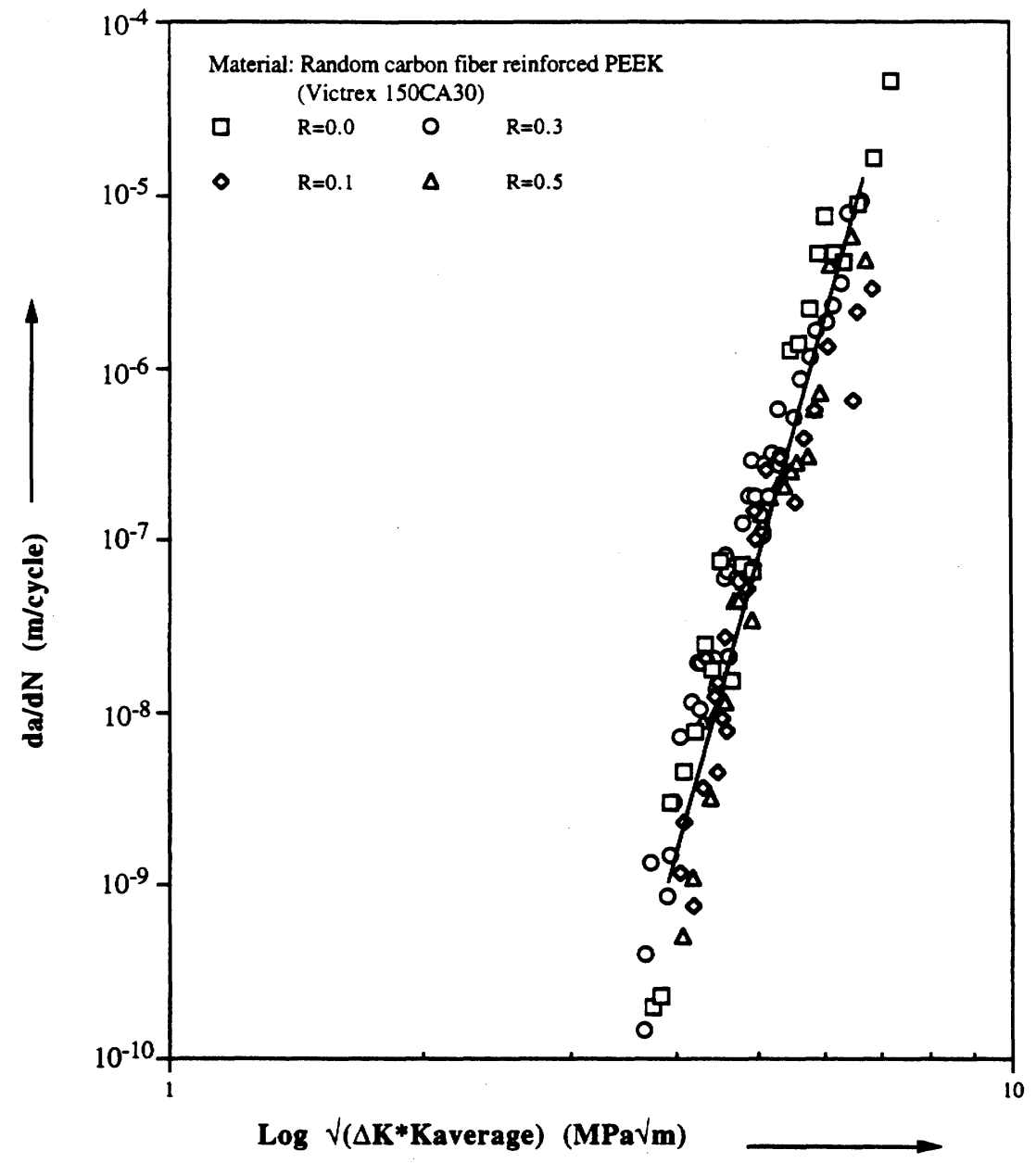

Figure 7. Effect of load ratio on fatigue crack growth behavior when computed against $\sqrt{ }(\Delta \mathrm{K}$. Kaverage). 


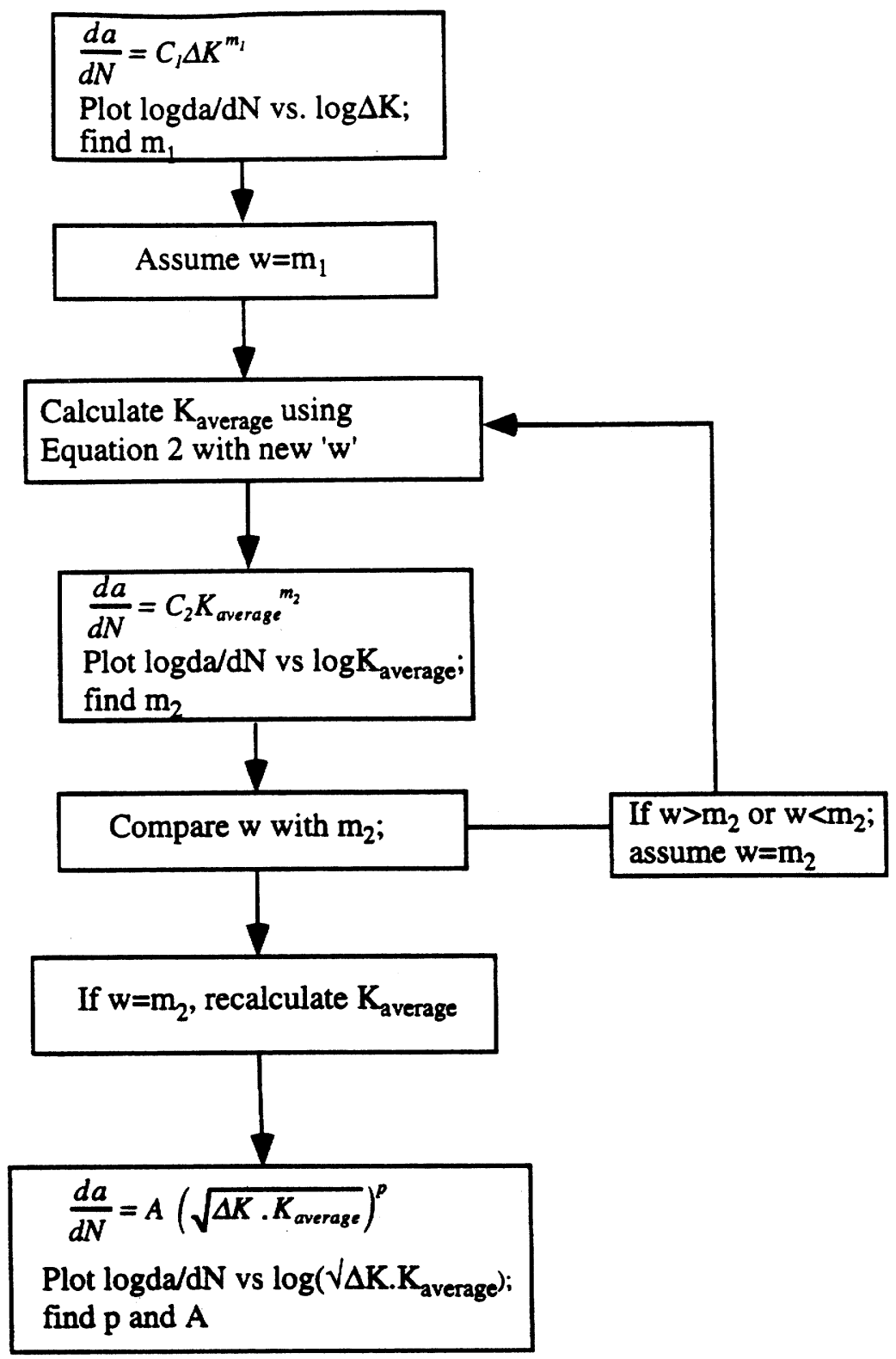

Figure 8. Algorithm used in iteration to find $\mathrm{K}_{\text {average }}$ and the power law exponents. 


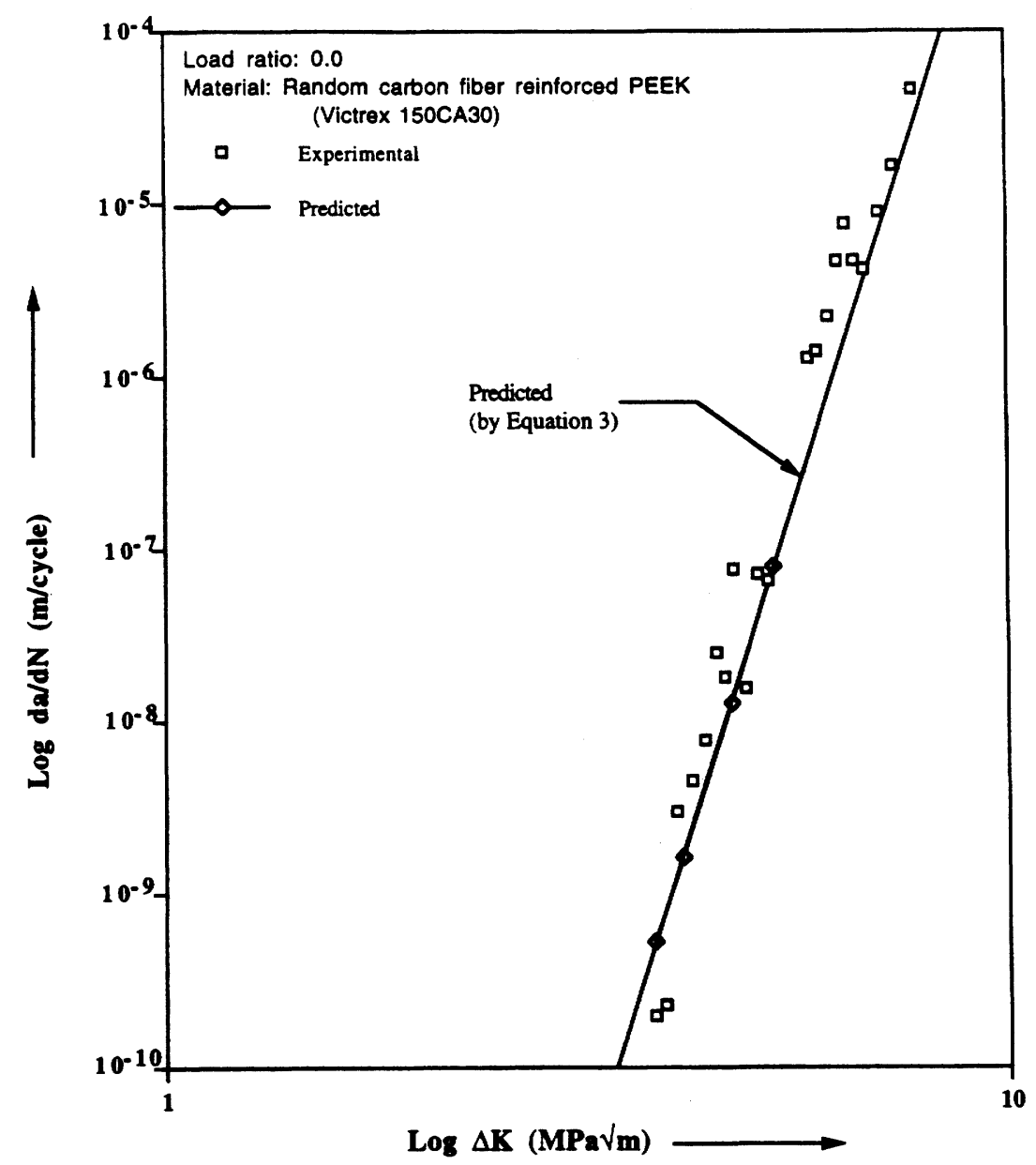

Figure 9. Fatigue crack growth behavior of random carbon fiber reinforced PEEK $(R=0)$. 


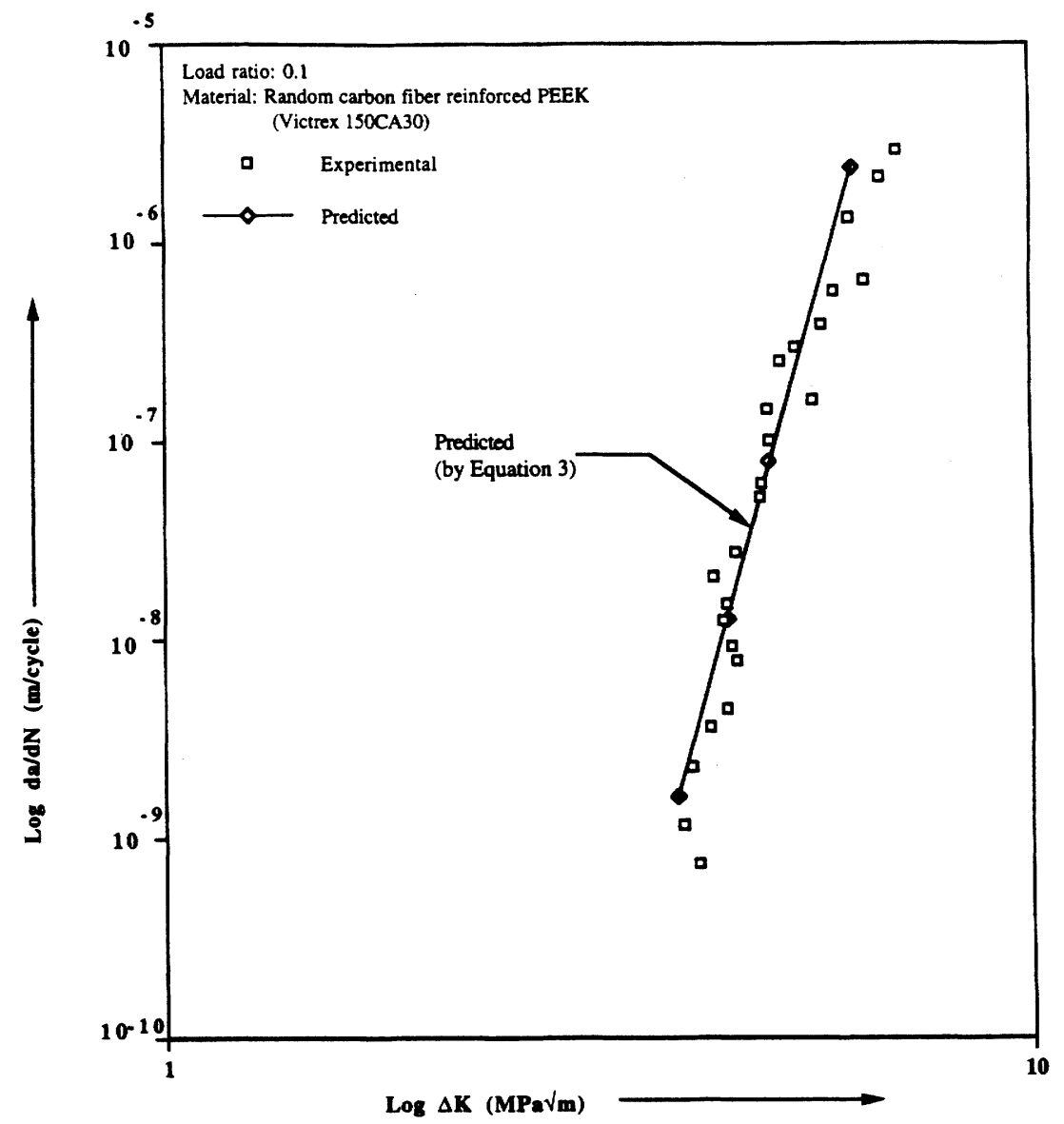

Figure 10. Fatigue crack growth behavior of random carbon fiber reinforced $P E E K(R=0.1)$. 


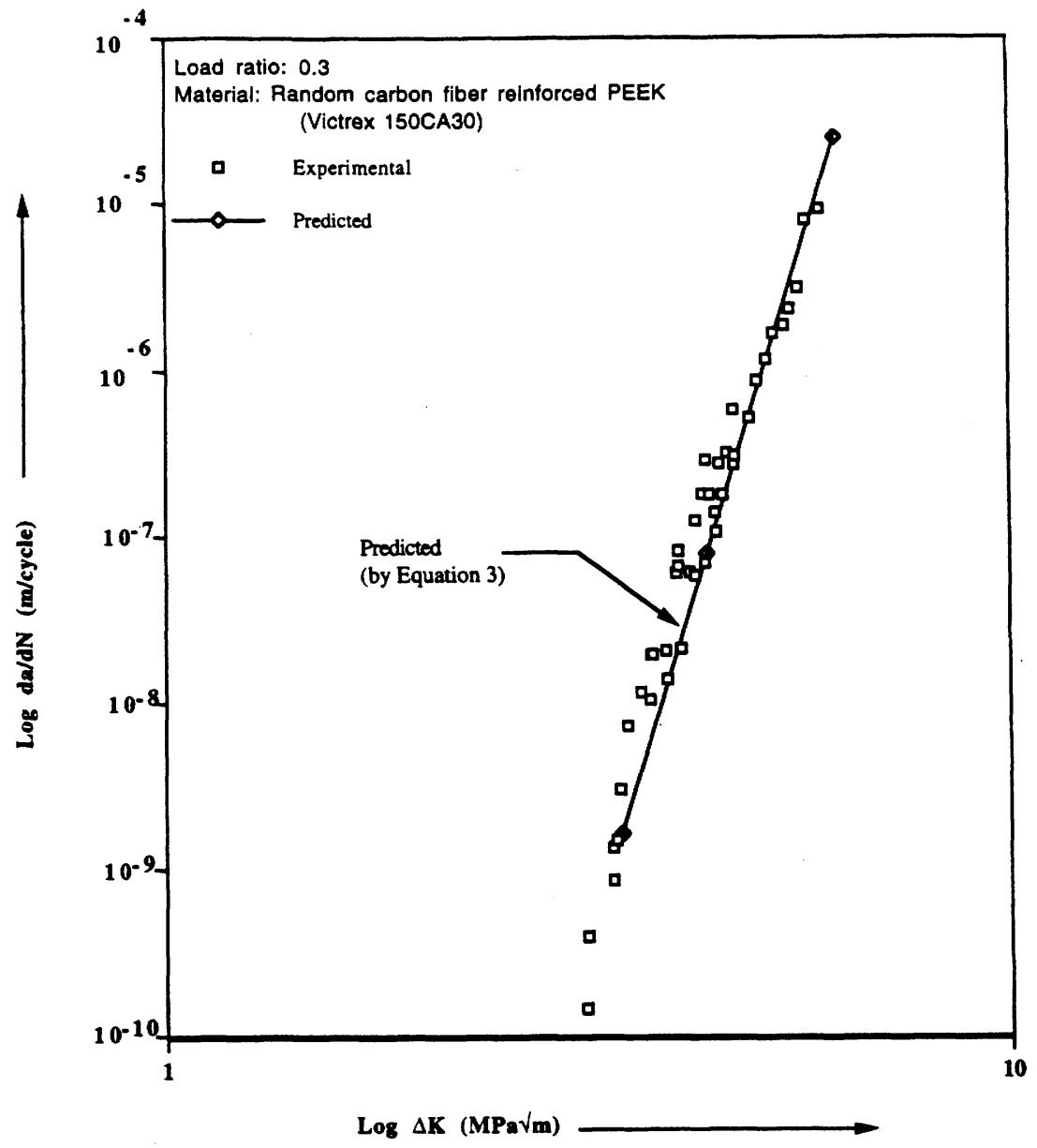

Figure 11. Fatigue crack growth behavior of random carbon fiber reinforced $P E E K(R=0.3)$. 


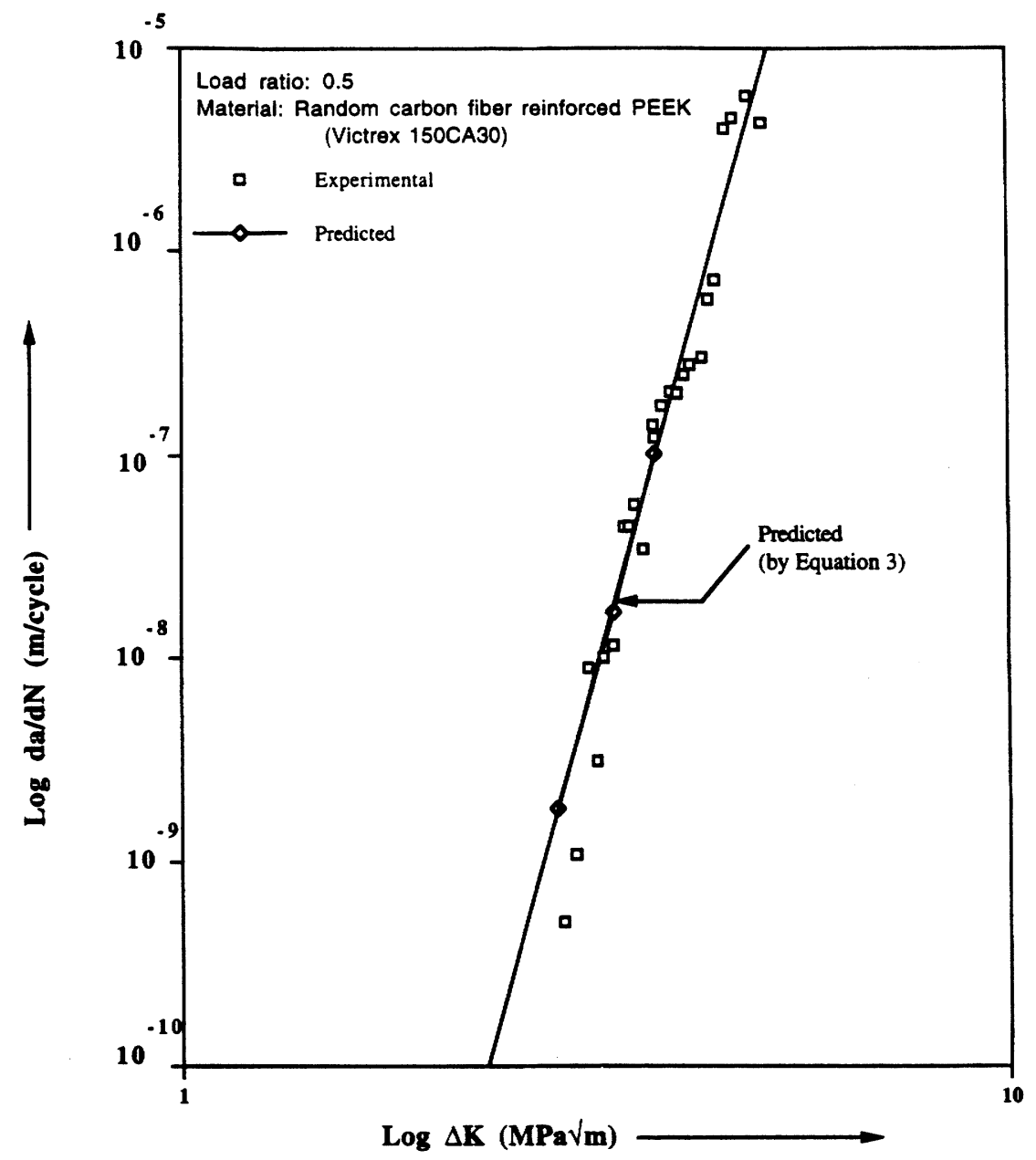

Figure 12. Fatigue crack growth behavior of random carbon fiber reinforced PEEK $(R=0.5)$. 


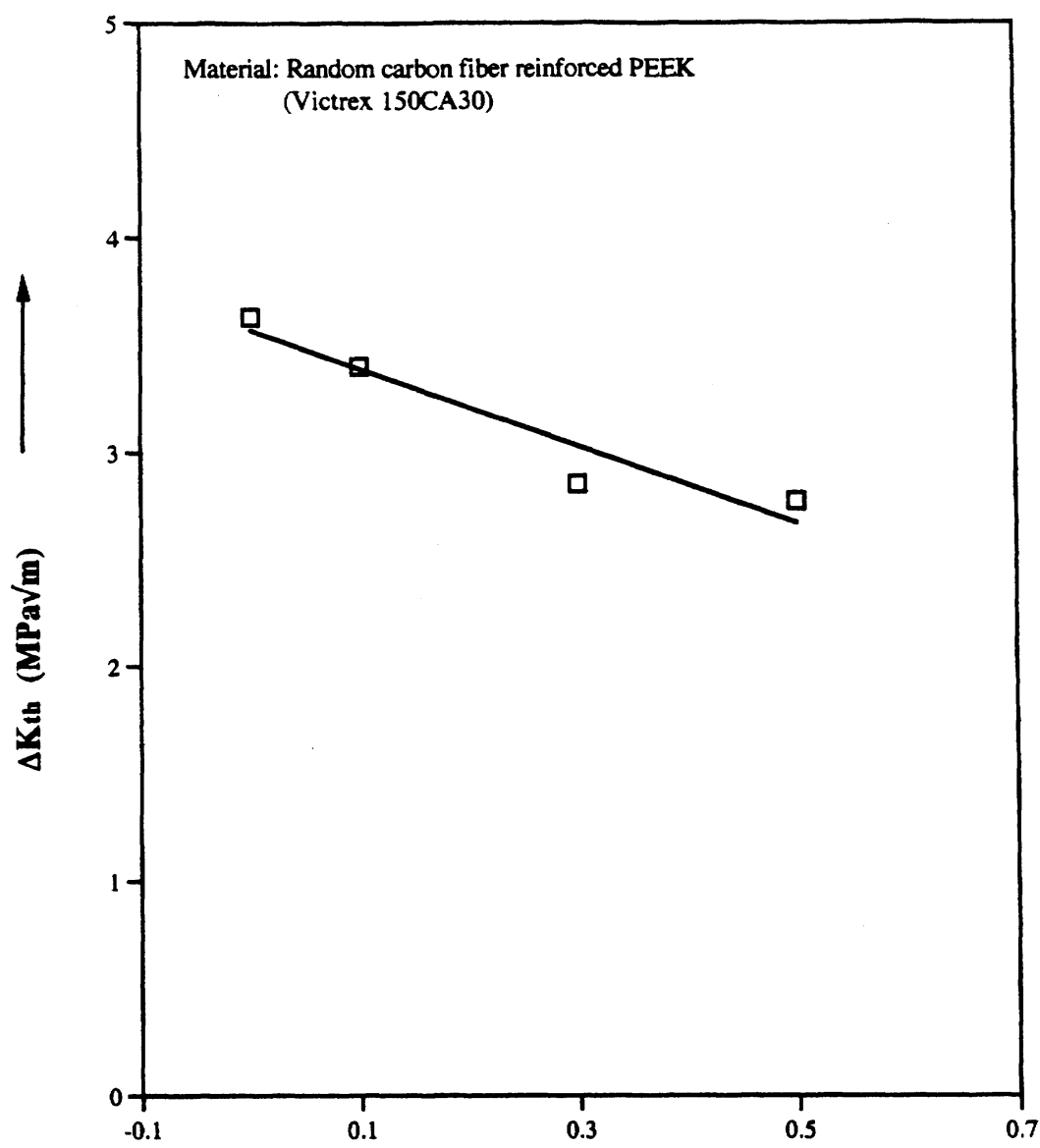

\section{Load Ratio, (R)}

Figure 13. Influence of load ratio on fatigue threshold of random carbon fiber reinforced PEEK. 
tablishing a power law relationship between the fatigue crack growth rate and $\sqrt{\Delta K \cdot K_{\text {average }}}$ at one load ratio.

\subsection{Fatigue Crack Growth Model}

Analogous to the Paris equation, the following power law equation is proposed to represent the data in Figure 7:

$$
\frac{d a}{d N}=A\left(\sqrt{\Delta K \cdot K_{\text {average }}}\right)^{p}
$$

An iterative procedure was used to determine the constant in Equation (3). The algorithm used in the iteration is outlined in Figure 8. The power law constants $A$ and $p$, in our case, were determined to be $5.43 \times 10^{-20}$ and 17.4 , respectively, using the combined data for all four load ratios. The fatigue crack growth rate data were plotted for the four separate load ratios in Figures 9-12 to examine the closeness of the data to Equation (3). In all four cases, a very close agreement was observed.

\subsection{Fatigue Threshold}

The stress intensity factors corresponding to the fatigue threshold of the PEEK composite are plotted against the load ratio in Figure 13. With increasing load ratio, there is a linear decrease in the fatigue threshold value. Many researchers $[7,8]$ have studied the influence of load ratio on the fatigue threshold in a wide variety of materials. Vosikovosky [7] analyzed the data from the literature and observed that in most cases, a linear relationship exists between the load ratio and the fatigue threshold. Similar behavior appears to hold true for the PEEK composite as well.

\section{CONCLUSIONS}

1. A new model for fatigue crack growth rate in random fiber composites has been proposed. The proposed model assumes that the fatigue crack growth in a random fiber composite occurs at all stress levels in a fatigue cycle as opposed to that occurring only at the maximum stress level.

2. The proposed model is capable of unifying the fatigue crack growth rate at the four load ratios investigated into one single power law equation:

$$
\frac{d a}{d N}=A\left(\sqrt{\Delta K \cdot K_{\text {average }}}\right)^{p}
$$

where, $K_{\text {average }}$ represents a weighted average of stress intensity factors in the fatigue cycle.

3. Good agreement was found between the predicted crack growth rate using the proposed model and the experimentally measured crack growth rate in randomly oriented short carbon fiber reinforced PEEK composite at four different load ratios.

4. The fatigue threshold stress intensity factor in the PEEK composite was found to decrease linearly with increasing load ratio. 


\section{REFERENCES}

1. Paris, P. C. and F. Erdogan. 1968. J. Basic Engineering, 85:528-537.

2. Wyzgoski, M. G. and G. E. Novak. 1995. Polymer Composites, 16:38-51.

3. Dibenedetto, A. T. and G. Salee. 1979. Polymer Engineering and Science, 19:512-518.

4. Wang, S. S., E. S.-M. Chim and N. M. Zahlan. 1983. J. Composite Matls, 17:250-266.

5. Dowling, N. E. 1993. Mechanical Behavior of Materials, Englewood Cliffs, NJ: Prentice Hall.

6. ASTM E-647. 1995. "Test Method for Determining of Plane Strain Fracture Toughness of Metallic Materials," Annual Book of ASTM Standard, 0.3.01.

7. Vosikovosky, O. 1972. Engineering Fracture Mechanics, 11:595-606.

8. Barsom, J. M. 1974. W. R. C. Bulletin, 194:123-126. 